\title{
The Potential of Keratinolytic Fungi for Biotechnological Applications in Leather Manufacture
}

\author{
MARIANA CALIN ${ }^{1}$, IULIANA RAUT ${ }^{1}$, MIHAELA DONI ${ }^{1}$, ELVIRA ALEXANDRESCU ${ }^{1}$, GABRIELA MACOVESCU ${ }^{2}$, \\ MELANIA LILIANA ARSENE ${ }^{1}$, ANA MARIA GURBAN ${ }^{1}$, GELU VASILESCU ${ }^{1}$, LUIZA JECU* \\ ${ }^{1}$ National Institute for Research \& Development in Chemistry \& Petrochemistry - ICECHIM, Biotechnology \& Bioanalysis Group, \\ 202 Spl. Independentei, Bucharest, Romania \\ ${ }^{2}$ National Research and Development Institute for Textile and Leather - Leather and Footwear Research Institute,93 Ion \\ Minulescu Str., 031215, Bucharest, Romania
}

\begin{abstract}
Keratinophilic fungi are present in soil as decomposers of keratinous substrates, while keratinolytic fungi have the capacity to decompose native keratin, the insoluble fibrous proteins from living organism. Keratin materials, especially by-products from food industry and animal husbandry must be harnessed through innovative, non-polluting and low-cost solutions. The nonpathogenic keratinolytic fungal species produce extracellular keratinases which have many and various applications, one being in leather industry where dehairing process of skin and hides require keratinolytic activity. The present study investigates the biodegradative potential of selected keratinolytic fungal microorganisms expressed towards different types of animal skins. The ability of Fusarium sp. I A strain to produce keratinase with a good activity towards animal skins was confirmed. These results suggest that after further studies, Fusarium sp.1A could play an important role in processing of animal wastes.
\end{abstract}

Keywords: collagenolytic activity, keratinases, keratinolytic fungi, leather manufacture

Keratinophilic fungi are able to colonize keratin materials in the soil and other natural environments [1-4]. The process occurs with different rates depending on ability of involved microorganisms, characteristics and availability of keratinaceous substrates. Keratinophilic fungi belonged to Ascomycetes and Deuteromycetes genera are present in soil as decomposers of keratinous substrates (chicken feathers and similar, hair, horns, nails, hoofs), some of them being pathogens causing a series of fungal infections in animals and humans, especially those from dermatophytes group.

Keratinolytic fungi are considered to be the decomposers of native keratin, the insoluble fibrous proteins from living organism. Industrial and agricultural activities lead to the accumulation of keratin wastes causing environmental problems. Keratin materials, especially by-products from food industry and animal husbandry must be harnessed through innovative, non-polluting and low-cost solutions. There are many reports on the biotechnological approach through keratinolytic fungi and secreted keratinases that could play a key role in valorisation of keratin wastes [5-7]. In particular, extracellular keratinases produced by nonpathogenic fungal species are becoming more and more useful in various applications, thus there is of interest to isolate and characterize new keratinolyic microorganisms with degradative potential. One important potential application of keratinases is in leather industry, dehairing process of skin and hides requiring keratinolytic activity [8-12]. It is known that pre-tanning and tanning processes contribute $80-90 \%$ of the total pollution in the industry generating hydrogen sulfide from the sodium sulfide the most used unhairing agent and chrome sludge from chromium sulphate. A significant contribution to the environmental protection would be the development of an eco-friendly bioprocess-based dehairing to reduce toxic wastes [13-15].

In our previous study, it has been reported the selection of fungal isolates able to degrade certain keratin substrates [16]. This prompted us to extent the investigation to evaluate the biodegradative potential of selected fungal microorganisms expressed towards different types of animal skins. Calfskin, sheepskins and sheep fur were chosen as a model mixture of collagen and keratin wastes discarded by the leather and fur industries. Microscopic observations (optical and scanning electronic microscopy) and enzymatic determinations were applied to assess the biodegradative process.

\section{Experimental part \\ Microorganism}

The fungal strains Fusarium sp. $1 \mathrm{~A}$ and Cladosporium sp. belonging to Microbial Collection of Microbiology Laboratory from INCDCP-ICECHIM were isolated from soil. The strains were kept on Potato Dextrose Agar slants at $4^{\circ} \mathrm{C}$.

\section{Keratin substrates}

Calfskin, sheepskins and sheep leather were used in tests. The sheepskin was transformed into fur in a succession of many complex stages emploing chemicals and tannins. (data under protection of patent application). All samples purchased from locally breeding animals presented hairs embedded in skins (Fig 1). The animal samples were sterilized three times, at $121^{\circ} \mathrm{C}$, for $15 \mathrm{~min}$, and then, kept at room temperature in a dry place.

\section{Culture conditions}

Cultures were carried out in $750 \mathrm{~mL}$ Erlenmeyer flasks with $200 \mathrm{~mL}$ of mineral basal medium with the following composition ( $\mathrm{g} / \mathrm{L})$ : $0.1, \mathrm{KH}_{2} \mathrm{PO}_{4}$ (Riedel-de-Haen, Germany); $0.1 \mathrm{CaCl}_{2}$ (Reactivul, Romania); 0.1, $\mathrm{FeSO}_{4} 7 \mathrm{H}_{2}$ (Reactivul, Romania); 0.005, ZnSO $7 \mathrm{H}_{2} \mathrm{O}$ (Reactivul, Romania); $\mathrm{pH}=7.5$. The culture medium was autoclaved at $121^{\circ} \mathrm{C}$, for $15 \mathrm{~min}$, and then, after cooling, supplemented with a piece of animal skin $(5 \times 5 \mathrm{~cm})$ and finally inoculated with $2 \times 10^{6}$ conidia per $\mathrm{mL}$. The flasks were incubated on rotary shaker Heidolph Unimax 1010, at $80 \mathrm{rpm}$ and $27^{\circ} \mathrm{C}$, for 21 days. A set of control flasks were run in tests: basal 


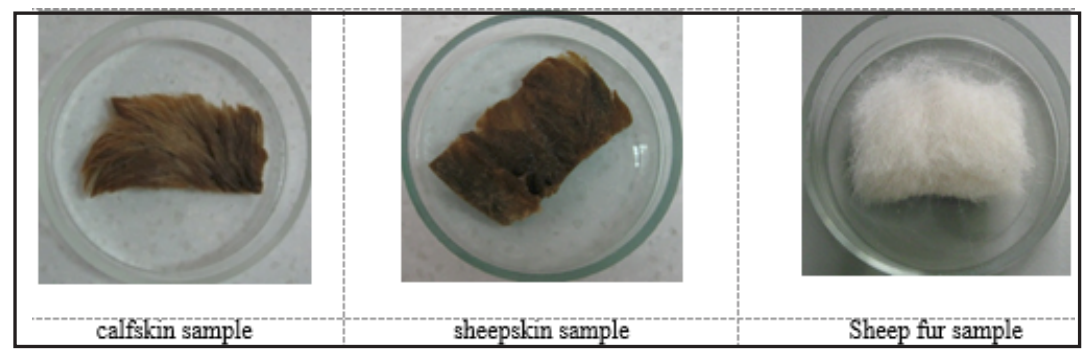

Fig. 1. Samples of animal skins used in experiments

mineral medium with keratin substrate and without microbial strain; basal mineral medium with microbial strain without keratin substrate. At the end of incubation period (21 days), the skin samples were removed, the cultures were centrifuged $\left(5.000 \times \mathrm{g}, 10 \mathrm{~min}, 4^{\circ} \mathrm{C}\right)$, and the supernatants were analyzed for enzymatic activity.

\section{Keratinase activity}

The keratinase activity in culture supernatants was determined using keratin azure (Sigma- Aldrich) [17]. Keratin was frozen for 24 hours at $0^{\circ} \mathrm{C}$ and then ground into a fine powder (Oscillating Mill with milling balls, MM 400, RETSCH). The substrate solution comprised $5 \mathrm{mg}$ keratin azure powder in $1 \mathrm{~mL} 50 \mathrm{mM}$ Tris - HCl buffer $(p \mathrm{H}$ 8.0). The reaction mixture contained $1 \mathrm{~mL}$ keratin azure suspension and $1 \mathrm{~mL}$ fungal culture filtrate. The control comprised a $1 \mathrm{~mL}$ keratin azure suspension and $1 \mathrm{~mL}$ basal medium. The reaction mixture was incubated in a shaking water bath (170 rpm) at $37^{\circ} \mathrm{C}$ overnight. The reaction was stopped by adding $1 \mathrm{~mL}$ trichloroacetic acid (10\% v/v) (Sigma Aldrich). After centrifugation at 3000 rpm for 15 min at room temperature, the absorbance of supernatant was determined at $595 \mathrm{~nm}$ (Biomate 3, Thermo Spectronic).

The enzymatic activity was calculated with the following formula:

Keratinase activity $(K A)=\left(A b s_{595(\text { sample) }}-A b s_{595 \text { (control) }}\right) 0.01$.

One unit (KA) keratinase activity was defined as the amount of enzyme causing 0.01 absorbance increase between the sample and control at $595 \mathrm{~nm}$ under given conditions.

\section{Collagenolytic activity}

Both strains were screened for collagenolytic activity on agar Petri plates (diameter $60 \mathrm{~mm}$ ) on tw o media with the following compositions (g/L) [10]: i) medium C1, collagen (bovine tendon d'Achile, Merck), 20, agar (Carl ROTH, Germany), $\mathrm{pH}=7.2-7.5$; ii) medium $\mathrm{C} 2$, collagen (bovine tendon d'Achile, Merck), 20, agar (Carl ROTH, Germany), 0.05, $\mathrm{CaCl}_{2}$ (Reactivul, Romania), 0.5, $\mathrm{NaH}_{2} \mathrm{PO}_{4}$ (Avantor POCH ${ }^{\mathrm{TM}}$, Poland), 0.5, $\mathrm{K}_{2} \mathrm{HPO}_{4}$ (Riedel-de-Haën, Germany); $p H=7.2-7.5$. The Petri plates were incubated at $37^{\circ} \mathrm{C}$ for $48 \mathrm{~h}$. Each individual colony was spreaded with a drop of mercuric chloride reagent containing $15 \mathrm{~g}_{\text {of }} \mathrm{HgCl}_{2}$ (Sigma-Aldrich), $20 \mathrm{~mL}$ of concentrated $\mathrm{HCl}$ and distilled water up to the volume of $100 \mathrm{~mL}$. The enzyme activity is indicated by the appearance of clear zonearound the colony of microorganism [18].

\section{Morphological and structural aspects}

The fungal growth and the evaluation of substrate biodegradation were observed by light microscopy with Olympus BX51 and Scanning Electron Microscopy (SEM) on a FEI-QUANTA 200 microscope in INCDCP-ICECHIM laboratories.

\section{Results and discussions}

The experiments were carried out with calfskin, sheepskin and sheep fur chosen as a model mixture of collagen and keratin wastes discarded by the leather and fur industries. Generally it is considered that the fresh hides or skins consist of water (64\%), proteins (33\%), fatty materials (2\%) and some mineral salts $(0.5 \%)$, and others mechanical impurities. The most significant for leather industry are the proteins which may consist of types as: i) structural proteins (the most important being collagen $29 \%$; elastin- $0.3 \%$, and keratin - $2 \%$ ); ii) non structural proteins (albumins and globulins, mucins and mucoids). The protein collagen, consisting of amino acids wound together to form triple-helices to form of elongated fibrils, displays a discrete structural hierarchy, from the molecular to microscopic levels. The netw ork of collagen fibers forms the corium or so-called skin proper [19]. One of the most commonlyused leathers due to its soft texture and distinct grain is calf leather produced from the calfskin. Sheepskin is used to produce sheep furs and soft wool-lined clothing or coverings, with good insulating properties, resistance to flame and static electricity.

In present study, several relevant samples of animal skins were kept in contact with two keratinolytic fungal strains for 21 days. After this period of incubation, the animal keratin samples suffered some modifications due to the biodegradative activity of fungal strains (Fig.2.).

Both sheepskin and sheep fur were more easily degraded by fungal strains as compared with calfskin, the sheepskin being partially digested. Among tested strains, Fusarium sp. 1A was more active against all animal skin samples, while Cladosporium sp. presented a relative growth on keratin samples with a higher activity against sheepskin samples. Figure 3 and 4 illustrate the observations on optical microscopy showing the good growth of both fungal strains. The hyphae of Cladosporium sp. have grown around the hair strand like a sleeve (Fig.3a, c), or like an embroidery woven between hair stands (Fig.3b, d). On treated sheepskin sample, Cladosporium sp. filaments produced a hyphae network as a blanket covering the hairs strands (Fig 3e, f).

A suggestive image of the effect of keratinolytic Fusarium sp. 1A strain upon animal strands hair from optical microscopic investigation is the lifting of cuticular scales (Fig 4a). A strong hair strand from sheepskin sample was broken (Fig. 3b). Also Fusarium sp. 1A produced many pieces of broken hair strands widespread among intact strands (Fig. 3c, d, e, f).

For a more detailed examination of animal skin samples, the scanning electronic microscopic method was used (Fig. 5 and 6). The samples that were not in contact with fungal strains presented the intact animal hair strands (Fig. $5 a, d)$, or unaffected cuticles of strand structure for sheep fur sample (Fig. $5 \mathrm{~g}$ ).

After incubation with Cladosporium sp. (Fig 5.), it can be observed several hyphae network attached on hair 


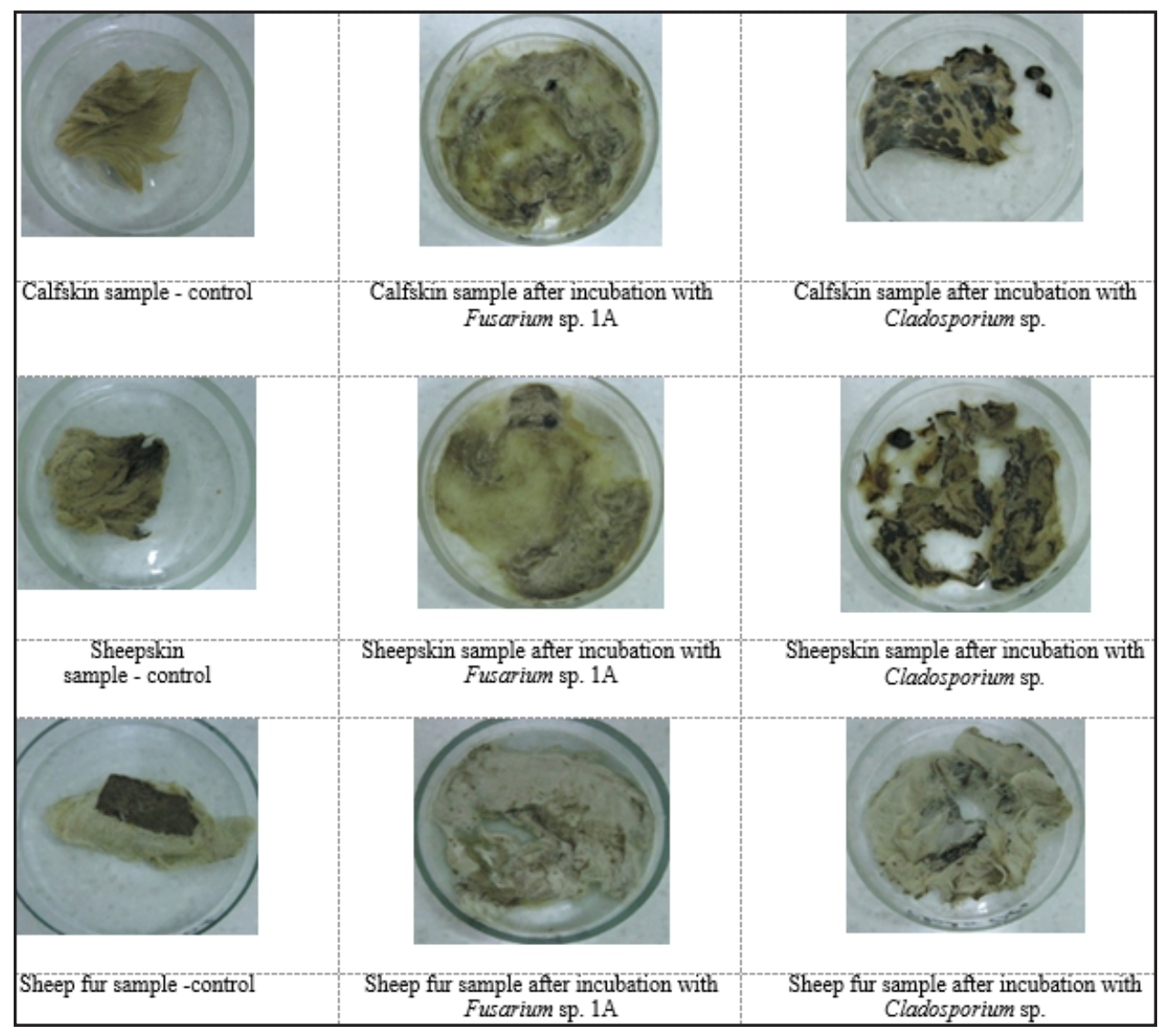

Fig. 2. Animal skins samples after incubation in liquid culture medium with or without microorganisms (controls)

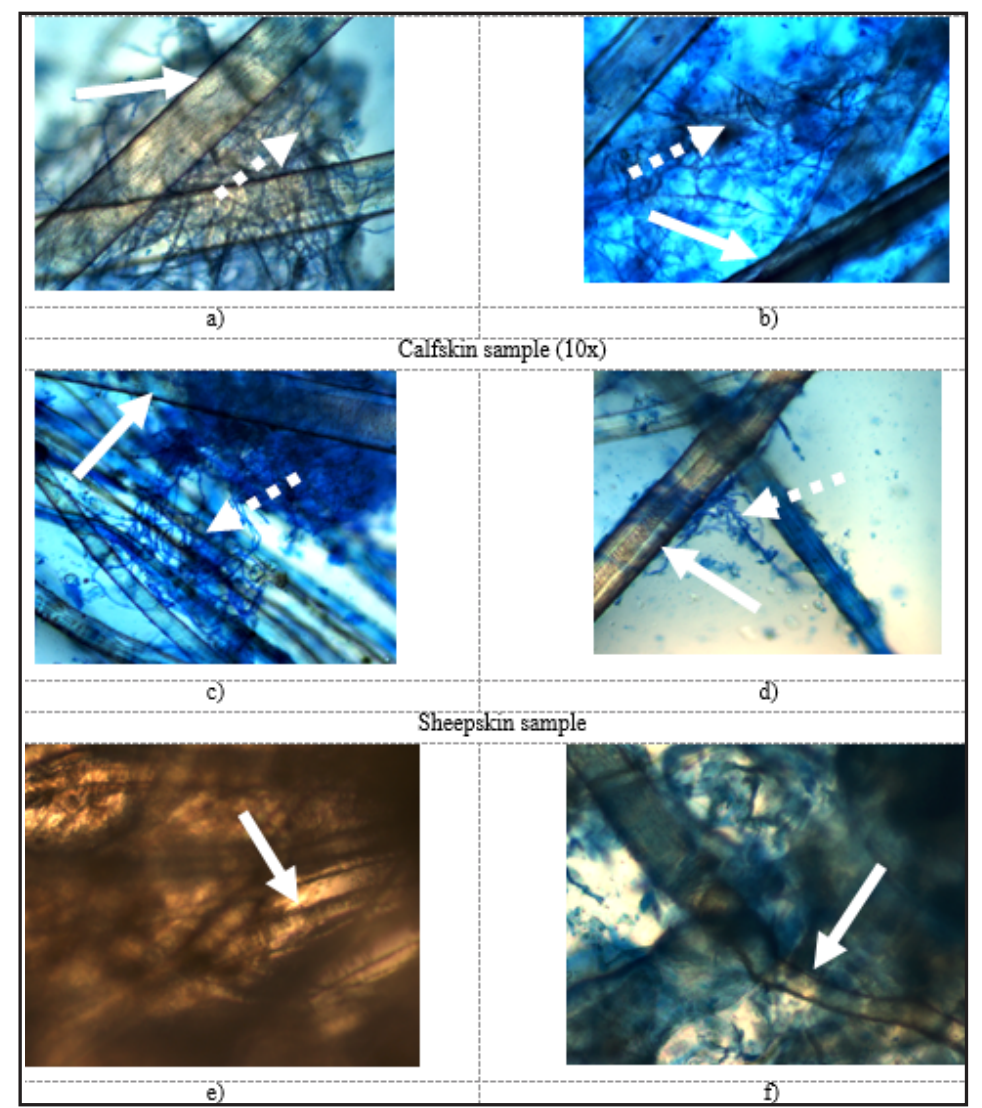

Fig. 3. Optical microscopy images of animal skin samples after incubation with Cladosporium sp. (10x; lactophenol blue cotton) (white arrow - strand hair from animal skin sample; white dotted arrow - hyphae network growing on and between hair strands)

strands (Fig $5 \mathrm{c}$ ), some stretching between strands (Fig. $5 \mathrm{~h}$ ), or, covering the strands like a blanket (Fig 5i). Also, it can be seen many broken hair strands (Fig 5i). Micrographs of skin samples incubated with Fusarium sp. only in basal medium are presented in Fig 6a, $6 \mathrm{~b}$ and $6 \mathrm{~g}$. Fusarium sp. 1A strain produced strong hyphae network surrounding hair strands (Fig. $6 \mathrm{c}$ and $6 \mathrm{i}$ ). It seems that Fusarium sp. 1A has produced more broken hair strands (Fig $6 \mathrm{~b}, 6 \mathrm{f}$ and $6 \mathrm{~h}$ ) as compared with Cladosporium sp. (Fig 5). Moreover, the aspects of micrograph (Fig 6h) could be considered dehairing of animal skin by enzymes of Fusarium sp. 1A strain.

The evaluation of keratinase activity is presented in Fig. 7. To note that the enzymatic activity of Fusarium sp. 1A was higher than that produced by Cladosporium sp., regardless the type of keratin substrate used in tests. The highest enzymatic activity was obtained with Fusarium sp. 1A in medium containing sheep fur (18.4 KA), followed 

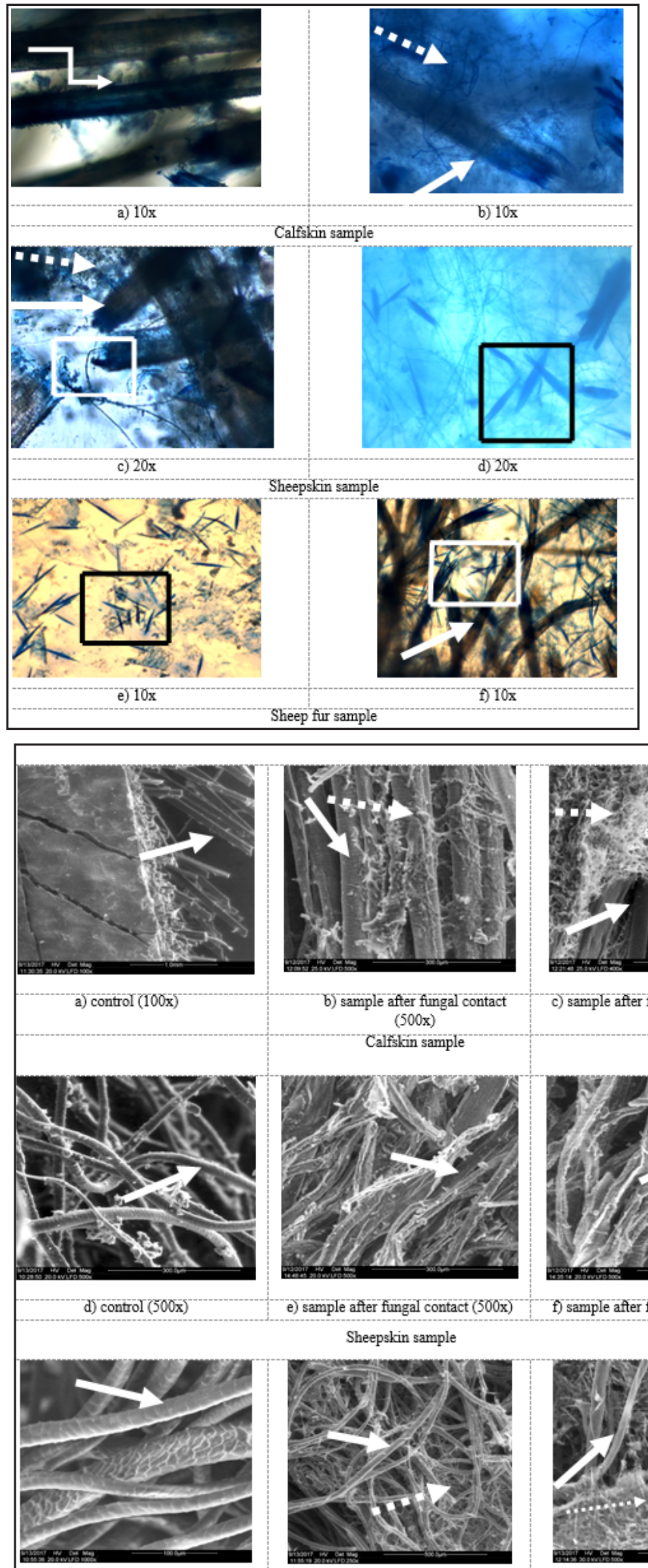

g) control $(1000 \mathrm{x})$

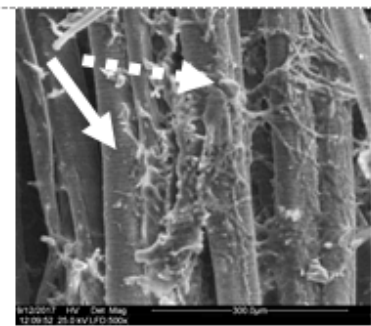

b) sample after fungal contact $(500 \mathrm{x})$ Calfskin sample

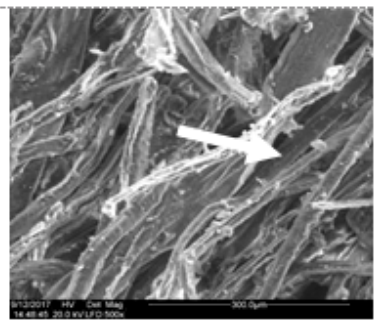

e) sample after fungal contact (500x)

Sheepskin sample

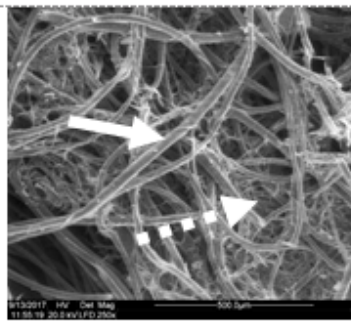

h) sample after fungal contact $(250 \mathrm{x})$

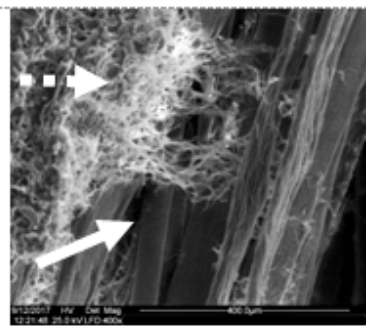

c) sample after fungal contact (400x)

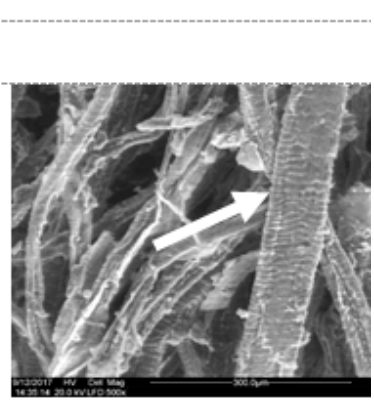

f) sample after fungal contact $(500 \mathrm{x})$

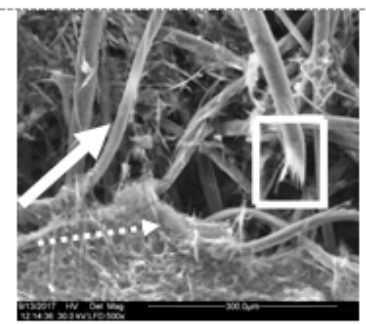

1) sample after fungal contact $(500 \mathrm{x})$

Sheep fur sample

Fig. 5. SEM images of animal skin samples after incubation with Cladosporium sp. (white arrow strand hair from animal skin sample; white dotted arrow - hyphae network growing on and between hair strands; white parallelogram - broken hair strands) 


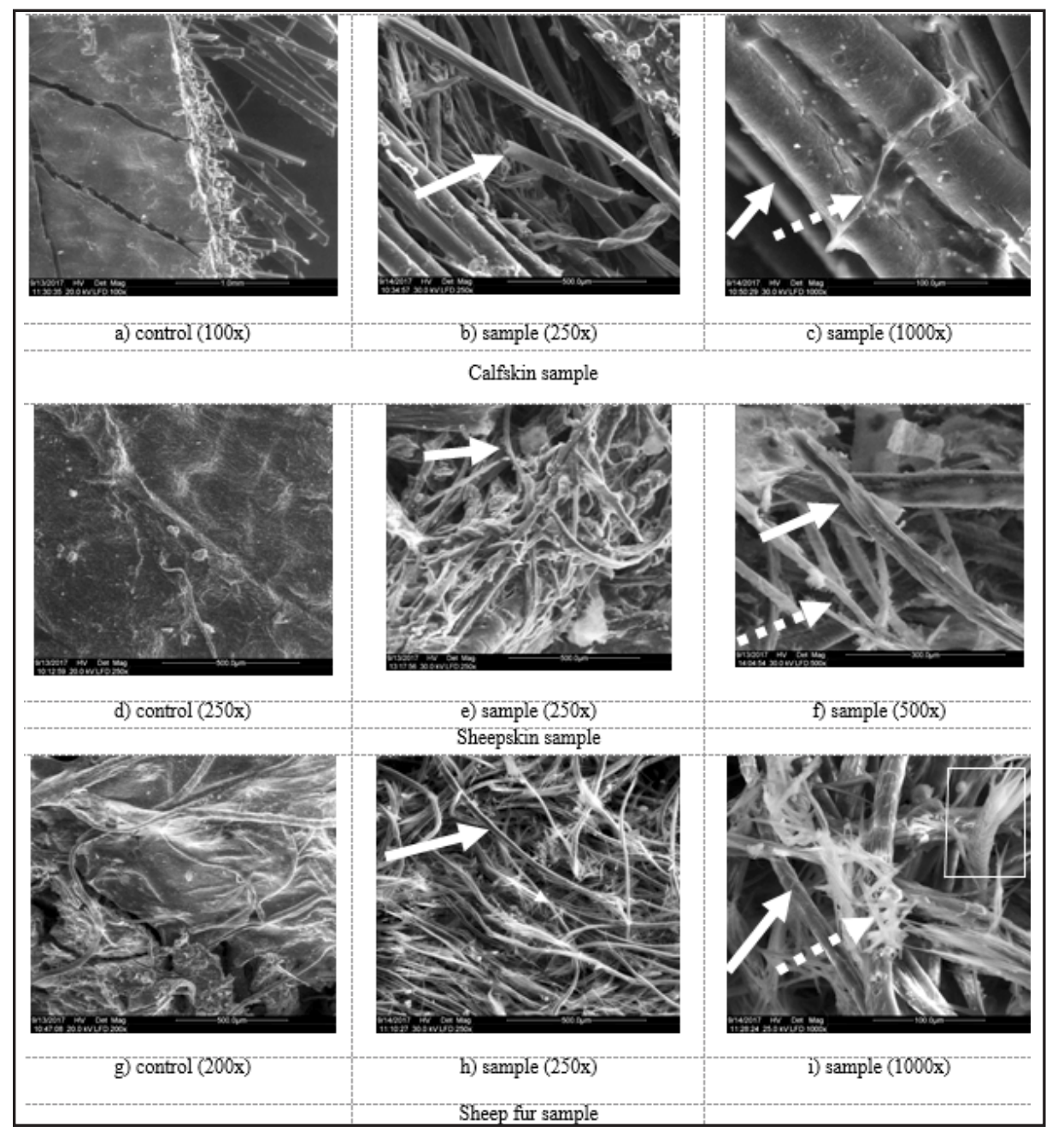

Fig. 6. SEM images of animal skins after incubation with Fusarium sp.

(white arrow - strand hair from animal skin sample; white dotted arrow - hyphae netw ork growing on and between hair strands; white parallelogram - broken hair strands)

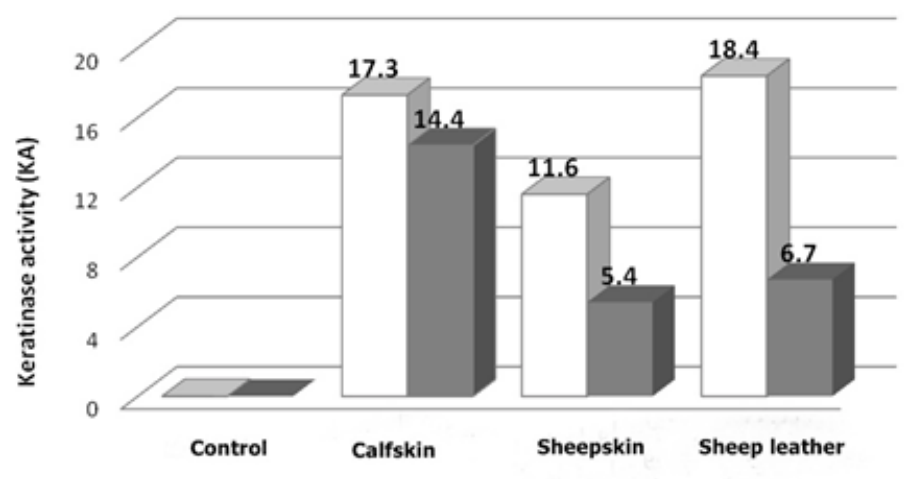

Fig. 7. Enzymatic keratinase activity of fungal strains in media with different animal skin samples

$\square$ Fusarium sp. = Cladosporium sp.

by that activity resulting on medium with calfskin (17.3 $\mathrm{KA}$ ).

Several reports are available on the filamentous fungi belonging to several genera that are able to grow on keratinous substrates and to be produce extracellular keratinases $[15,20,21]$, some to be of interest for practical applications [22, 23].

In leather industry, bating process involves keratinolytic and elastolytic activities to accomplish the degradation of keratin and elastin. Meanwhile, the characteristics of leather are improved through the treatment with collagenases which opens up the collagen fibers for a better diffusion of dyes into collagen network, for making soft and durable leather. On the other hand, itis known that too active collagenases could negatively affect the leather quality, with the potential danger of collagen matrix, especially the grain layer [24-27]. From pollution point of view, the replacement of chemicals with enzymes is a complex process which needs further efforts to be

accomplished. At present, the mechanism of enzymatic dehairing is vaguely understood from the point of view of the enzyme specificity [28]. Considering these issues, a preliminary qualitative investigation was carried out by culturing both fungal isolates on a solid media containing collagen. The enzymes secreted by microorganisms act by broking down the collagen molecule into smaller molecules that can be taken up as nutrients to feed the microbial growth. The colonies and the transparent circles resulted from test on collagen solid medium are presented in Fig. 8.

The presence of a clear zone around the fungal colonies showed a relative collagenase activity secreted into the cultivation media. As compared with others reported results [29], the tested strains seem to be not very good producers of collagenase activity. The absence or a low level of collagenase activity will be a criterion for the fungal strain to be selected to be used in leather manufacture with minimizing collagen damage [30]. 


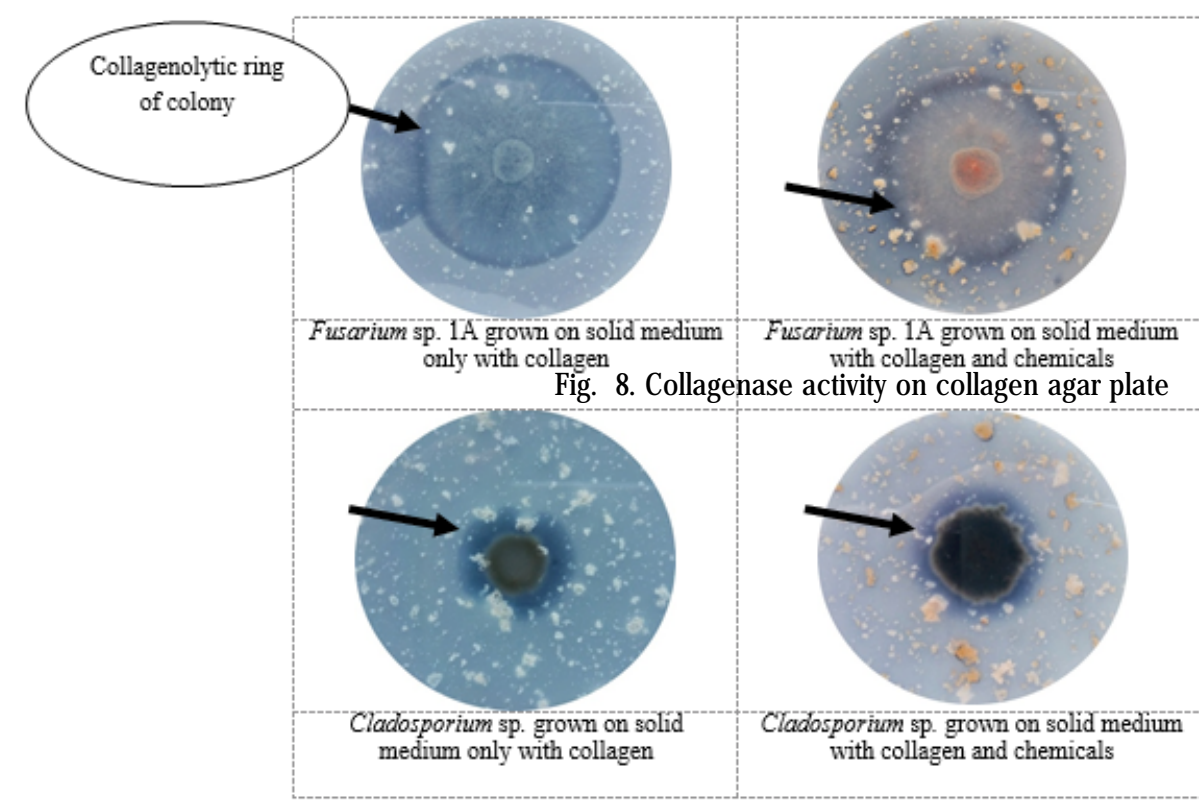

Fig. 8. Collagenase activity on collagen agar plate

\section{Conclusions}

The objective of the present investigation was to evaluate the biodegradative potential of selected fungal microorganisms expressed towards different types of animal skins. The evidence of optical and SEM observations confirmed the modifications suffered by animal keratin samples due to the activity of fungal strains. Fusarium sp. $1 A$ strain produced keratinases with a good activity towards all animal skins used in experiments. A high enzymatic activity was obtained with this strain cultured in medium containing sheep fur (18.4 KA), followed by the activity on medium with calfskin (17.3 KA). Fusarium sp. $1 \mathrm{~A}$ was selected based on the level of keratinase production as well as in connection to relative low collagenolytic activity. Fusarium sp.1A could playan important role in the process of hydrolysis of animal wastes after some improvements in production and activity of extracellular keratinases.

Acknowledgments: The authors wish to thank dr. Diana AruxandeiConstantinescu for valuable discussions and effort in running keratinase assay. The authors also thank to Ministry of Research and Innovation through Program 1- Development of the National Research $\&$ Development System, Subprogram 1.2 -Institutional performance Projects of Excellence Financing in RDI, project number PFE no 31/ 2018.

Funding:These scientific works were financial supported through project PN 18.22.01.01 Nucleu Program.

\section{References}

1. SHARMA, R., RAJAK, R. C., Resonance, 8, 2003, nr. 9, p. 28.

2. KORNILLOWICZ-KOWALSKA, T., BOHACZ, J., Waste Manag., 31, 2011, p. 1689.

3. BLYSKAL, B., Internat. Biodeter. Biodegrad., 63, 2009, p. 631. 4. KORNILLOWICZ-KOWALSKA, T., KITOWSKI, I., Acta Mycol, 46, 2011, nr. 1, p. 83.

5. GOPINATH S. C. B., ANBU P., LAKSHMIPRIYA T., TANG T. H., CHEN Y., HASHIM U., RAHIM R. A., ARSHAD M. K., Hindawi Publishing Corporation BioMed Res. Int, Volume 2015, Article ID 140726, http:// dx.doi.org/10.1155/2015/140726.

6. VERMA A., SINGH H., ANWAR S., CHATTOPADHYAY A., TIWARI K. K., KAUR S., DHILON G. S., Crit. Rev. Biotechnol., 37, 2017, nr. 4, p. 476. 7. BERECHET, M.D., NICULESCU, M. D., GAIDAU, C., IGNAT, M., EPURE, D. G., Rev. Chim.(Bucharest), 69, no. 7, 2018, p. 1649.

8. PILLAI, P., ARCHANA, G., Appl. Microbiol. Biotechnol., 78, 2008, p. 643.

9. MACEDO A. . ., DA SILVA W. O. B. D., GAVA R., DRIEMEIER D., JAP H., TERMIGNONI, C., Appl. Environ. Microbiol., 71, 2005, p. 594.
10. THANIKAIVELAN P., RAO J. R., NAIR B. U., RAMASAMI T., Trends in Biotechnol., 22, 2004, nr. 4, p. 181;

11. GOUSTEROVAA., BRAIKOVA D., GOSHEV I., CHRISTOV P., TISHINOV K., VASILEVA-TONKOVA E., HAERTLE T., Letter Appl. Microbiol., 40, 2005, p. 335.

12. PANTAZI, M., STEFAN, D. S., CONSTANTINESCU, R., ANGHEL, R., MEGHEA, A.,VASILESCU, A. M., Rev. Chim. (Bucharest), 65, no.2, 2014, p.233.

13. ZAMBARE V. P., NILEGAONKAR S. S., KANEKA P. P., World J. Microb. Biotechnol., 23, 2007, p. 1569.

14. P. PRAKASH, S. K. JAYALAKSHMI, K., SREERAMULU, Appl Biochem Biotechnol., 160, 2010, p. 1909.

15. ALEXANDRE J . M., WALTER O., BEYS D. S., RENATA G., DAVID D., JOAO A., PEGAS H., CARLOS T., Appl. Environ. Microbiol., 71, 2005, p. 594.

16. CALIN M, CONSTANTINESCU-ARUXANDEI D., ALECSANDRESCU E., RAUT I., BADEA DONI M., ARSENE M. L., OANCEA F., JECU L., V LAZAR V., Electronic J. Biotechnol., 28, 2017, p. 101.

17. KAZI Y. F., KUMAR P., SOOMRO I. H., Afr. J. Biotechnol., 12, 2013, nr. 14, p. 1669.

18. LIU L., MA M., CAI Z., YANG X., WANG W., Food Technol. Biotechnol. 48, 2010, nr. 2, p. 151.

19. KADLER K. E., BALDOCK C., BELLA J., BOOT-HANDFORD R. P., J. Cell Sci., 120, 2007, nr. 12, p. 1955.

20. ALI T. H., ALI N. H., MOHAMED L. A., J. Appl. Sci. Environ. Sanitation, 6, 2011, nr. 2, p. 123.

21. SABER W. I. A., EL-METWALLY M. M., EL-HERSH M. S., Res. J. Microbiol., 5, 2010, nr. 1, 21-35.

22. KOTWAL S., SUMBALI G., Springer Plus (2016) 5:1204 DOI 10.1186/ s40064-016-2874-.

23. KANNAHI. M., ANCY. R. J ., J. Chem. Pharm. Res., 4, 2012, nr. 6, p. 3245.

24. MALATHI S., CHAKRABORTY R., Appl. Environ. Microbiol., 57, 1991, p. 712.

25. GEORGE N., SONDHI S., SONI S. K., GUPTA N., Indian J . Microbiol., 54, 2014, nr. 2, p. 139.

26. NAJAFI M. F., DEOBAGKAR D., DEOBAGKAR D., Electronic J. Biotechnol., 8, 2005, p. 198.

27. HADDAR A., HMIDET N., GHORBEL-BELLAAJ O., FAKHFAKHZOUARI N., SELLAMI-KAMOUN A., NASRI M., Biotechnol. Bioproc. Eng., 16, 2011, p.669.

28. SUJITHA P., KAVITHA S., SHAKILANISHI S., BABU N. K. C., SHANTHI C., Int. J. Biol. Macromol., 118, 2018, p. 168.

29. WANDERLEY M. C. A., NETO J. M. W. D., FILHO J. L. L., LIMA C. A., TEIXEIRA J. A. C., PORTO A. L. F., Braz. J. Microbiol., 48, 2017, p. 1324.

30. GEORGE, N. SONDHI, S., SONI, S. K., GUPTA, N., Indian J, Microbiol, 54, 2014, nr. 2, p. 139.

Manuscript received: 8.11 .2018 